ONLINE MUTATION REPORT

\title{
NIPBL mutations and genetic heterogeneity in Cornelia de Lange syndrome
}

\author{
G Borck, R Redon, D Sanlaville, M Rio, M Prieur, S Lyonnet, M Vekemans, N P Carter, A Munnich, \\ L Colleaux, V Cormier-Daire
}

J Med Genet 2004;41:e128 (http://www.jmedgenet.com/cgi/content/full/41/12/e128). doi: 10.1136/jmg.2004.026666

C ornelia de Lange syndrome (CdLS, also called Brachmann de Lange syndrome; OMIM 122470) is characterised by pre- and postnatal growth retardation, microcephaly, severe mental retardation with speech delay, feeding problems, major malformations including limb defects, and characteristic facial features. ${ }^{1}$ Facial dysmorphism includes arched eyebrows, synophrys, short nose with anteverted nares, long philtrum, thin upper lip, and micrognathia. Although few autosomal dominant forms of CdLS have been described, ${ }^{23}$ the large majority of cases are sporadic, and the scarcity of these familial forms has hampered the identification of the gene(s) underlying CdLS. ${ }^{4}$ Finally, rare cases of CdLS have been associated with balanced chromosomal translocations. ${ }^{5-7}$

A gene responsible for CdLS has been recently identified by two groups. Indeed, Krantz et al performed genome-wide linkage exclusion mapping in 12 CdLS families and identified a locus on chromosome $5 \mathrm{p} 13 .{ }^{8}$ This locus mapped close to both a translocation breakpoint and a small de novo deletion associated with CdLS. Studying the 5 pl3 translocation breakpoint allowed both groups to identify a disrupted gene which they called NIPBL, for Nipped-B like. ${ }^{8}$ NIPBL is the human homolog of the Drosophila Nipped-B gene, the product of which belongs to the family of chromosomal adherins. The Drosophila Nipped-B protein is involved in chromatid cohesion processes and enhancer-promoter communication. ${ }^{10}{ }^{11}$ The exact function of the human NIPBL gene product, called delangin, is unknown, but its wide expression pattern, including expression in embryonic limb bud, branchial arch, and craniofacial mesenchyme, is consistent with many of the anomalies observed in CdLS. NIPBL mutations have been identified in $20-50 \%$ of CdLS cases, ${ }^{8}{ }^{9}{ }^{12}$ suggesting that some mutations may have escaped detection and/or that CdLS is genetically heterogeneous.

To address this question, we performed a comprehensive clinical, cytogenetic, and molecular study in 14 affected children. Our results show that NIPBL mutations are present in only $35 \%$ of CdLS cases, strongly suggesting the genetic heterogeneity of this syndrome.

\section{METHODS \\ Patients}

The series included 14 children (seven boys and seven girls) ranging in age from 14 months to 17 years. All patients were regularly followed at the Department of Medical Genetics of the Necker - Enfants Malades Hospital, Paris. They were diagnosed with CdLS on the basis of four major criteria: (i) pre- and/or postnatal growth retardation, (ii) microcephaly, (iii) moderate to profound mental retardation with abnormal speech development, ranging from minimal speech to complete absence of speech, and (iv) facial dysmorphic features including arched eyebrows with synophrys, short nose with anteverted nares, long philtrum, and thin upper lip. In addition, at least two of the following four clinical

\section{Key points}

- Cornelia de Lange syndrome (CdLS) is characterised by facial dysmorphism, microcephaly, growth and mental retardation, and congenital anomalies including limb defects. Mutations in the gene NIPBL, the human homolog of Drosophila Nipped-B, have recently been found in $20-50 \%$ of CdLS cases.

- We extensively analysed a series of 14 children with CdLS. The study included a high resolution chromosome analysis, a search for small chromosome imbalances using array-CGH at $1 \mathrm{Mb}$ resolution, and direct sequencing of the 46 NIPBL coding exons.

- Chromosomal or molecular anomalies most likely causing CdLS were found in $7 / 14$ cases. Chromosome analysis detected an isochromosome $18 p$ of paternal origin in a girl with a mild CdLS phenotype. Array-CGH analysis detected a de novo submicroscopic deletion of terminal chromosome lq in a girl with severe manifestations of CdLS. We identified five heterozygous de novo NIPBL mutations including one splice site (IVS2+1G $>$ A), one frameshift (95delT), two missense (N2236I, L2092V) mutations, and a deletion of three nucleotides (leading to N2218del).

- We conclude that NIPBL mutations account for $\sim 35 \%$ of CdLS cases in our series. The absence of a NIPBL mutation in more than $50 \%$ of children with CdLS and the observation of two distinct chromosomal anomalies is highly suggestive of genetic heterogeneity.

signs or symptoms were required for diagnosis, namely: (i) behavioural problems including self injurious behaviour, hyperactivity, repetitive and autistic behaviour, (ii) feeding problems and/or gastroesophageal reflux, (iii) major or minor anomalies of the upper limbs, and (iv) skin anomalies, particularly hirsutism and cutis marmorata. Table 1 and fig 1 summarise our clinical findings in the 14 patients included in the study.

Two patients presented with unusual features, namely absence of corpus callosum (patient 2) and long palpebral fissures/prominent malar region (patient 6; fig 1), but both met the inclusion criteria including the typical behavioural phenotype.

Mean paternal and maternal age at birth of the affected child was 33 (range 24-45) and 30 (range 19-40) years, respectively. Three fathers and four mothers were over 40 and 35 years of age at the birth of their CdLS child, respectively.

Abbreviations: CdLS, Cornelia de Lange syndrome; DAPI, 4', 6'diamidino-2-phenylindole 
Table 1 Clinical features in $14 \mathrm{CdLS}$ patients

\begin{tabular}{|c|c|c|c|c|c|c|c|c|c|c|c|c|c|c|c|}
\hline & 1 & 2 & 3 & 4 & 5 & 6 & 7 & 8 & 9 & 10 & 11 & 12 & 13 & 14 & Total \\
\hline Gender & $\mathrm{F}$ & $\mathrm{F}$ & $\mathrm{F}$ & $\mathrm{F}$ & $M$ & $M$ & $\mathrm{~F}$ & $\mathrm{~F}$ & $M$ & $M$ & $M$ & $\mathrm{~F}$ & $M$ & $M$ & $7 M / 7 F$ \\
\hline Familial recurrence & - & - & $\begin{array}{l}\text { Aff. } \\
\text { brother }\end{array}$ & - & - & - & - & $\begin{array}{l}\text { Aff. } \\
\text { father }\end{array}$ & $r^{-}$ & - & - & - & - & - & 2 \\
\hline $\begin{array}{l}\text { Age at last } \\
\text { examination (years) }\end{array}$ & 7 & 9 & 4 & 1 & 8 & 11 & 10 & 1 & 3 & 8 & 2 & 8 & 6 & 17 & $1-17$ \\
\hline IUGR & + & + & + & + & + & + & + & - & + & + & + & + & + & - & $12 / 14$ \\
\hline $\begin{array}{l}\text { Postnatal growth } \\
\text { retardation }\end{array}$ & + & + & + & + & + & + & + & + & + & + & + & + & + & + & $14 / 14$ \\
\hline Microcephaly & + & + & + & + & + & + & + & + & + & + & + & + & + & + & $14 / 14$ \\
\hline Mental retardation & + & + & + & + & + & + & + & + & + & + & + & + & + & + & $14 / 14$ \\
\hline $\begin{array}{l}\text { Speech delay }(+) \\
\text { or absent speech }(++)\end{array}$ & + & ++ & ++ & + & ++ & + & + & + & + & + & + & ++ & ++ & + & $14 / 14$ \\
\hline Facial dysmorphism & & & & & & & & & & & & & & & $14 / 14$ \\
\hline Arched eyebrows & + & + & + & + & + & + & + & + & + & + & + & + & + & + & \\
\hline Synophrys & + & + & + & + & + & + & + & + & + & + & + & + & + & + & \\
\hline Short nose & + & + & + & + & + & + & + & + & + & + & + & + & + & - & \\
\hline Anteverted nares & + & + & + & + & + & + & + & + & + & + & + & + & + & + & \\
\hline Long philtrum & + & + & + & + & + & + & + & + & + & + & + & + & + & + & \\
\hline $\begin{array}{l}\text { Thin upper lip } \\
\text { Other }\end{array}$ & + & + & + & + & + & $\begin{array}{l}+ \\
\text { Long palpe- } \\
\text { bral fissures, } \\
\text { prominent } \\
\text { malar region }\end{array}$ & + & + & + & + & + & + & + & + & \\
\hline $\begin{array}{l}\text { Behavioural } \\
\text { problems }\end{array}$ & $\begin{array}{l}\text { AA } \\
\text { HA } \\
\text { SD }\end{array}$ & $A D$ & $\mathrm{HA}$ & - & $\begin{array}{l}\text { HA } \\
\text { AA }\end{array}$ & $\mathrm{HA}$ & $\begin{array}{l}\text { AA } \\
\text { SD }\end{array}$ & - & - & $\mathrm{HA}$ & $\mathrm{HA}$ & $A D$ & $\begin{array}{l}A D \\
A A\end{array}$ & $A D$ & $11 / 14$ \\
\hline Feeding problems & + & + & + & + & - & + & + & + & + & + & + & + & + & + & $13 / 14$ \\
\hline GER & + & + & + & + & - & - & - & + & - & - & + & - & + & - & $7 / 14$ \\
\hline Limb anomalies & & & & & & & & & & & & & & & $14 / 14$ \\
\hline Short hands & + & + & + & + & + & + & + & + & + & + & + & + & + & + & \\
\hline $\begin{array}{l}\text { Clinodactyly } \\
\text { 5th finger }\end{array}$ & + & + & - & - & - & - & - & - & + & - & - & + & - & + & \\
\hline Limitation elbow & - & - & - & - & + & - & - & - & + & - & - & + & - & - & \\
\hline STC & - & - & - & + & + & - & - & - & - & - & - & - & - & - & \\
\hline Short feet & + & + & + & + & + & + & + & + & + & + & + & + & + & + & \\
\hline Syndactyly 2-3 & - & - & - & - & + & - & - & + & - & - & - & - & - & - & \\
\hline Hirsutism & - & + & - & - & + & - & - & + & + & + & + & + & + & + & $9 / 14$ \\
\hline $\begin{array}{l}\text { Cutis marmorata } \\
\text { Ear and eye }\end{array}$ & + & - & + & + & + & - & - & + & - & - & - & + & - & - & $6 / 14$ \\
\hline Deafness & - & + & - & - & - & - & NA & - & - & - & - & NA & $\begin{array}{l}\text { Altered } \\
\text { AEP }\end{array}$ & + & $2 / 12$ \\
\hline Strabismus & - & + & - & - & - & - & - & - & - & - & - & - & - & + & $2 / 14$ \\
\hline Ptosis & - & - & - & - & - & + & - & - & - & - & - & - & - & + & $2 / 14$ \\
\hline Nystagmus & - & - & - & - & - & - & - & - & + & - & - & - & - & - & $1 / 14$ \\
\hline Myopia & - & - & - & - & - & + & - & - & + & - & - & - & - & + & $3 / 14$ \\
\hline $\begin{array}{l}\text { Neurologic } \\
\text { anomalies }\end{array}$ & & & & & & & & & & & & & & & \\
\hline Seizures & + & + & + & - & - & + & - & - & - & - & - & - & - & - & $4 / 14$ \\
\hline $\begin{array}{l}\text { Cerebellar } \\
\text { hypoplasia }\end{array}$ & + & - & - & - & - & - & - & - & + & - & - & - & - & - & $2 / 14$ \\
\hline ACC & - & + & - & - & - & - & - & - & - & - & - & - & - & - & $1 / 14$ \\
\hline Cleft palate & - & - & - & - & - & + & - & - & - & - & - & - & - & + & $2 / 14$ \\
\hline GI malformation & $\begin{array}{l}\text { Hiatus } \\
\text { hernia }\end{array}$ & - & - & - & - & - & - & - & $\begin{array}{l}\text { Pyloric } \\
\text { stenosis }\end{array}$ & - & - & $\begin{array}{l}\text { Duodenal } \\
\text { atresia }\end{array}$ & - & - & $3 / 14$ \\
\hline Heart defect & - & ASD & - & ASD & - & $\begin{array}{l}\text { Mitral valve } \\
\text { prolapse }\end{array}$ & - & - & - & VSD & - & - & - & - & $4 / 14$ \\
\hline $\begin{array}{l}\text { Genito-urinary } \\
\text { anomaly }\end{array}$ & - & - & VUR & - & - & - & - & - & - & - & - & - & $\begin{array}{l}\text { Cryptor- } \\
\text { chidism }\end{array}$ & $\begin{array}{l}\text { Cryptor- } \\
\text { chidism }\end{array}$ & $3 / 14$ \\
\hline $\begin{array}{l}\text { Chromosome } \\
\text { anomaly }\end{array}$ & $i(18 p)$ & $\begin{array}{l}\text { del } \\
\text { lqter }\end{array}$ & - & - & - & - & - & - & - & - & - & - & - & - & $2 / 14$ \\
\hline NIPBL mutation & - & - & N2218delN & N2236I & L2092V & IVS2+1G >A & 95delT & - & - & - & - & - & - & - & $5 / 14$ \\
\hline
\end{tabular}

All children were of French ancestry except cases 8 (Algeria) and 11 (France/Algeria). Two cases of familial recurrence were observed (families 3 and 8). In family 3, an older brother of the proposita was also diagnosed with CdLS based on prenatal growth deficiency, microcephaly, and typical facial dysmorphism. This boy died 1 week after birth. In family 8, CdLS was apparently transmitted as an autosomal dominant trait as the proband's father had short stature, a learning disability, congenital heart disease, and dysmorphic features reminiscent of mild CdLS (fig 1).

\section{Cytogenetic studies and fluorescent genotyping}

Blood samples were collected for chromosome analysis and DNA extraction with written informed consent of the parents. Standard karyotypes using RHG and/or GTG banding and high resolution chromosome analyses after synchronisation and BrdU incorporation (RBG) were performed from peripheral blood lymphocytes of the patients following standard protocols.

For FISH analysis, we used the TelVysion probe panel mixture 12, containing in particular TelVysion $18 \mathrm{p}$ 

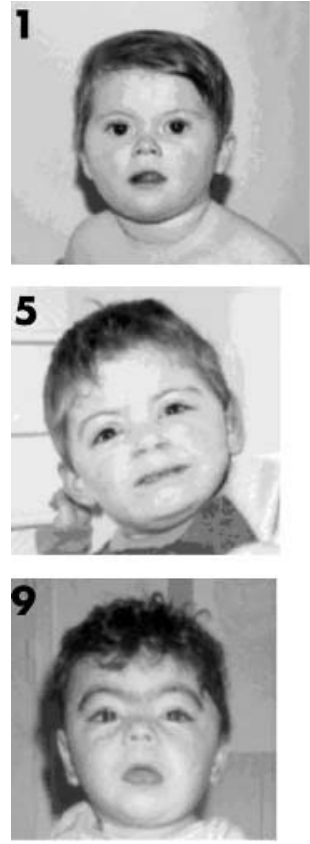
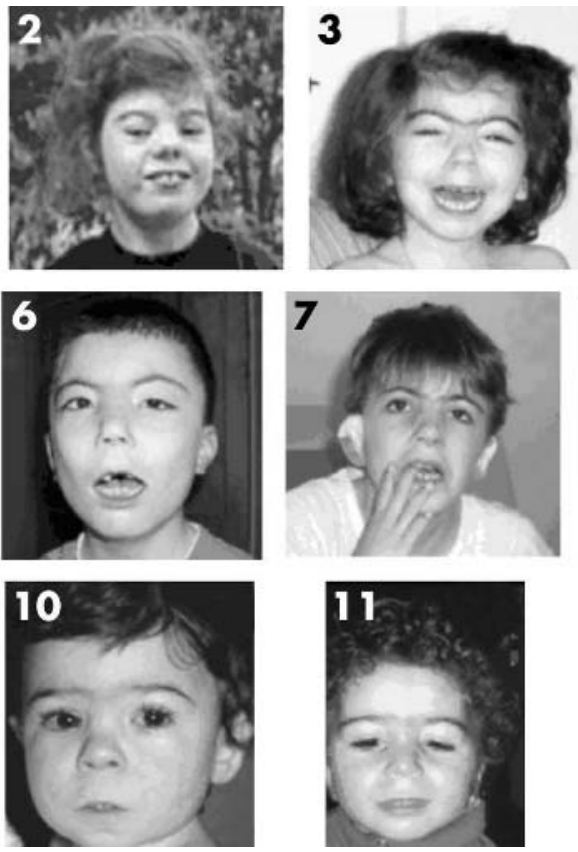
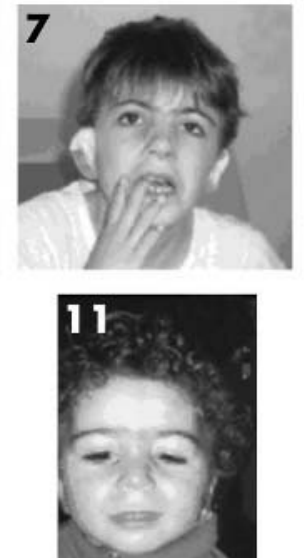
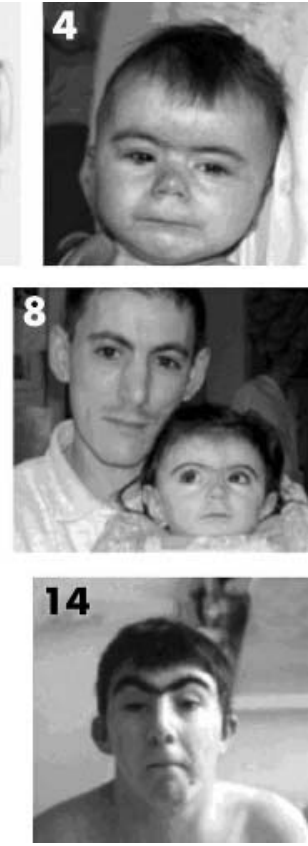

Figure 1 Facial views of CdLS patients. The numbers correspond to the patient's number in the text and the tables. Patients 1 and 2 have a chromosome anomaly, and patients 3-7 a hetereozygous NIPBL mutation. No anomaly was detected in patients 8-11 or 14. (Photographs are reproduced with consent.)

SpectrumGreen (telomeric clone) and CEP18 SpectrumAqua (alpha-satellite probe). Hybridisations were performed following the manufacturer's instructions (Abbott Diagnostics, Rungis, France). Chromosomes were counterstained with 4',6'-diamidino-2-phenylindole (DAPI). Image capture and analyses were performed using a Leica DMRXA epifluorescence microscope equipped with the appropriate filter combination for detecting SpectrumAqua, FITC, and DAPI. Images were captured by a cooled CCD camera using an image analysis system (Alphelys, Nikon). Fluorescent genotyping was performed as previously described.$^{13}$ We genotyped the following chromosome $18 \mathrm{p}$ microsatellite markers in family 1 : Dl8S59, D18S476, Di8S54, D18S52, Dl8S391, D18S1150, D18S53, and D18S453 (in order from telomere to centromere).

\section{NIPBL sequence analyses}

We designed 51 primer pairs to cover the 46 NIPBL coding exons (exons 2-47) and the corresponding exon-intron boundaries. The primers designed for exon 46 were chosen to include the 3 ' sequence specific for the NIPBL isoform B. ${ }^{9}$ Primer sequences and PCR conditions are available on request. PCR products were purified with Exo-SAP (Amersham, Orsay, France) and then directly sequenced in both directions on an ABI PRISM 3100 DNA sequencer (Perkin Elmer-Applied Biosystems, Courtaboeuf, France) using the dye terminator method according to the manufacturer's instructions.

\section{Array-CGH}

Because our study started prior to recent publications, ${ }^{8}{ }^{12}$ a $1 \mathrm{Mb}$ array-CGH search for submicroscopic deletions and duplications was performed in all 14 children. A total of 3523 clones were used for array construction, covering the genome with a $1 \mathrm{Mb}$ resolution. ${ }^{14}$ DOP-PCR products of each clone were arrayed in duplicate onto amine binding slides. Details on all spotted clones can be obtained from the Ensembl database (http://www.ensembl.org/Homo_sapiens/cytoview). DNA labelling, array hybridisation, washing, and image and data analyses were performed as described previously. ${ }^{15}$

\section{RESULTS}

\section{Chromosome imbalances}

Two children were found to have a de novo chromosome imbalance. The karyotype of a girl with a mild CdLS phenotype (patient 1; fig 1 and table 1) detected a supernumerary marker chromosome in 100 metaphases analysed, consistent in size and banding pattern with an isochromosome 18p. FISH analysis confirmed this finding (fig 2A) and array-CGH detected a gain of chromosomal material consistent with a tetrasomy of the entire chromosome 18p (data not shown). No other associated chromosome imbalance was identified and no anomaly was detected in the parents' DNA suggesting a de novo event. Genotypes of seven microsatellite markers of chromosome 18p showed a stronger intensity of

Table 2 Analysis of polymorphic microsatellite markers in family 2

\begin{tabular}{llllll}
\hline Marker & Position* $^{*}$ & Father & Patient 2 & Mother & Interpretation** $^{\text {** }}$ \\
\hline D1S321 & 238.1 & $159 / 161$ & $157 / 161$ & 157 & Biparental \\
D1S2842 & 239.1 & $220 / 226$ & 218 & $218 / 226$ & del pat \\
D1S2679 & 239.3 & $189 / 191$ & 197 & $189 / 197$ & del pat \\
D1S2836 & 243.1 & $268 / 270$ & 272 & $268 / 272$ & del pat \\
D1S2682 & 244.4 & $116 / 136$ & 116 & $116 / 136$ & $\mathrm{NI}$ \\
\hline
\end{tabular}

Allele sizes are given in base pairs. Genotypes consistent with a deletion are shown in bold.

*The position of microsatellite markers is given according to the University of Santa Cruz Genome browser (www.genome.ucsc.edu, accessed May 2004) in Mb from the short arm telomere; ${ }^{* *}$ del pat, deletion of the paternal allele; NI, non informative. 
A

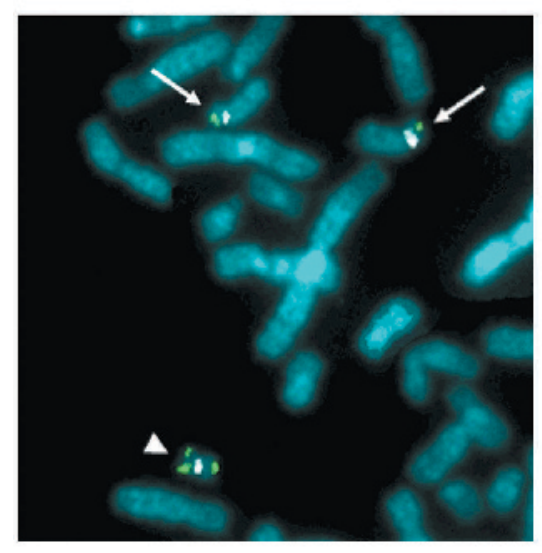

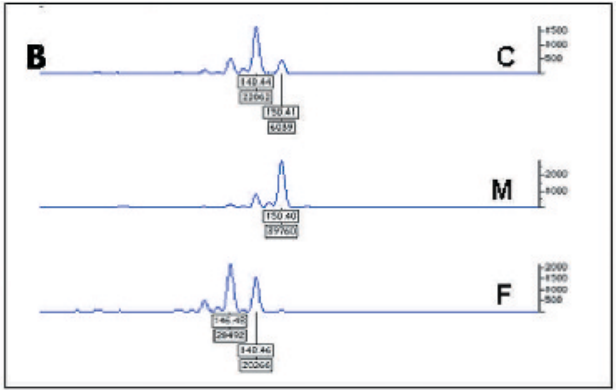

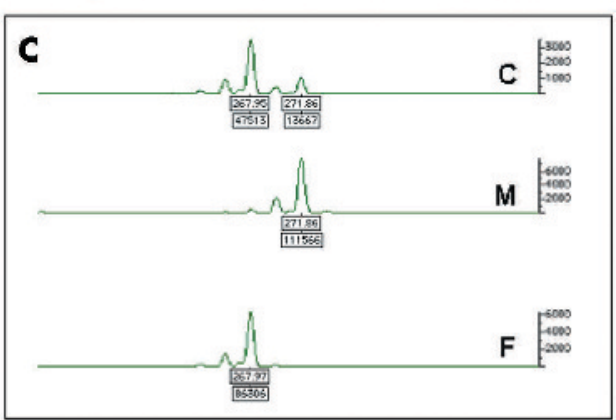

Figure 2 Detection of an isochromosome 18p of paternal origin in patient 1. (A) FISH analysis with centromeric (white) and telomeric (green) chromosome 18 specific probes. Arrows depict the two normal chromosomes 18. The monocentric isochromosome 18p is shown by an arrowhead. (B and C) Representative results of microsatellite analysis at loci D18S453 (B) and D18S476 (C) in family 1. C, M, and F stand for child, mother, and father genotypes, respectively. Numbers under the electropherograms indicate the length of the PCR products (in bp) and the area under the curve. Note the stronger intensity of the paternal allele compared to the maternal allele. Results for all other informative markers are comparable to those shown here.

the paternal allele, suggesting that the isochromosome $18 \mathrm{p}$ was of paternal origin (fig $2 \mathrm{~B}$ and $\mathrm{C}$ ).

In patient 2, a girl with severe manifestations of CdLS including severe mental retardation, autistic behaviour, seizures, and heart defect (fig 1 and table 1), array-CGH detected a subtelomeric deletion of chromosome lq encompassing the six most telomeric clones (fig 3). Microsatellite analysis confirmed this deletion and showed that it had occurred on the paternal allele (table 2). The deletion spanned 6.5 $\mathrm{Mb}$ and had occurred de novo. Retrospective analysis of her high resolution karyotype failed to detect this deletion.

No chromosome imbalances were found in the remaining 12 CdLS patients, but six genomic imbalances of single clones were noted which correspond to either polymorphisms inherited from healthy parents or small variants (data not shown).

\section{NIPBL mutations}

The microarray used for array-CGH contains a $188 \mathrm{~kb}$ long BAC clone (RP11-7M4) which encompasses the entire NIPBL coding sequence. The hybridisation pattern of this clone ruled out a large submicroscopic NIPBL deletion in the 14 CdLS children.

The direct sequencing of the 46 NIPBL coding exons detected five heterozygous mutations (patients 3-7): one splice site mutation (IVS2+lG>A), one frameshift mutation followed by a premature stop codon (95delT), one in-frame deletion of three nucleotides (leading to N2218del), and two missense mutations (N2236I, L2092V; table 3). The N2236I and L2092V mutations altered residues highly conserved across species (including rat, mouse, Tetraodon, and Drosophila) and were not detected in 110 and 280 alleles of control subjects, respectively. All mutations were found to

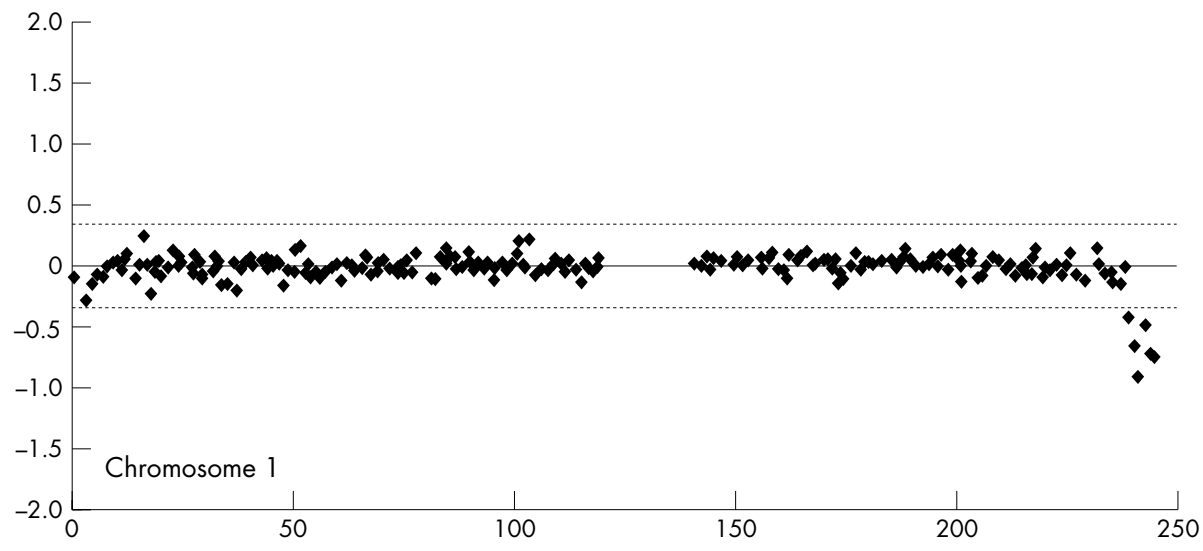

Figure 3 Identification of a subtelomeric deletion lq in patient 2. Array-CGH profile of chromosome 1. The $x$ axis marks the distance, in $\mathrm{Mb}$, from the $\mathrm{p}$ telomere. The $y$ axis marks the hybridisation ratio plotted on a $\log _{2}$ scale. Broken lines indicate thresholds for clone duplication and deletion ( \pm 4 SD). The following six clones at the chromosome 1q telomere are deleted: RP1 1-41 1G13 (240.2-240.3 Mb), RP1 1-13L16, RP1 1-399B15, RP1 1-551G24, RP1 1-438H8, and CTB-160H23 (245.8-246.0 Mb). 
Table 3 NIPBL mutations identified in CdLS patients

\begin{tabular}{|c|c|c|c|c|}
\hline Individual & Location of the mutation & Nature of the mutation & Mutation* & Effect on mRNA/protein \\
\hline 6 & Intron 2 & Splice mutation (splice donor site) & IVS2+1G >A (c.64+1G>A) & $\begin{array}{l}\text { Probable skipping of exon } 2 \text { which } \\
\text { contains the translation } \\
\text { initiation codon }\end{array}$ \\
\hline 7 & Exon 3 & 1 bp deletion & c.95delT & $\begin{array}{l}\text { Frameshift and stop codon } 14 \text { amino } \\
\text { acids downstream }\end{array}$ \\
\hline 3 & Exon 39 & 3 bp deletion & c. $6653 \_6655$ delATA & N2218delN \\
\hline 4 & Exon 39 & Missense & c. $6707 \bar{A}>T$ & N2236I \\
\hline 5 & Exon 36 & Missense & c. $6274 \mathrm{C}>\mathrm{G}$ & L2092V \\
\hline
\end{tabular}

have occurred de novo, as they were not detected in the parents of the affected individual. No NIPBL mutation was detected in the two children carrying a chromosome imbalance. Finally, we identified three sequence polymorphisms, including two already known and a novel intronic (IVS13-17A $>$ G) polymorphism.

\section{DISCUSSION}

Here, we report the thorough cytogenetic and molecular investigation of a series of 14 CdLS cases using standard and high resolution karyotyping, $1 \mathrm{Mb}$ resolution array-CGH, and NIPBL mutation screening. We found NIPBL mutations in $35 \%$ of our patients $(5 / 14)$. Their clinical manifestations were typical of CdLS except for some dysmorphic features in patient 6 . These results support the view that NIPBL is a major disease causing gene in CdLS. ${ }^{8}{ }^{12}$ The mutant genotypes described here are de novo mutations including splice site, frameshift, and missense mutations, and a small inframe deletion. The conservative L2092V substitution is most likely disease causing as it occurred de novo, affected a highly conserved amino acid residue, and was not present in a large control population. Interestingly, none of the mutations reported here have been described so far, supporting the broad allelic heterogeneity of NIPBL mutations in CdLS. ${ }^{8}{ }^{12}$

Among the five patients with NIPBL mutations, only one (patient 3) had a family history, but unfortunately no DNA from the other affected child was available. However, since the mutation was not found in their parents' DNA, the recurrence of CdLS in this family is most likely the consequence of a germinal mosaicism for the NIPBL mutation. Based on this observation, we suggest giving consideration to germinal mosaicism when counseling asymptomatic parents of children with CdLS.

It is important to note that we failed to detect NIPBL mutations in the majority of the cases in our series (9/14). Whether the disease causing mutation has been overlooked or another locus is involved in CdLS remains questionable. In support of the genetic heterogeneity of the disease, it is worth remembering that a recent linkage study detected positive LOD scores at single markers on chromosomes 2q37, 10p13, and $14 \mathrm{q} 24 .{ }^{8}$ Our study further supports genetic heterogeneity as two distinct de novo chromosomal anomalies were detected in CdLS patients with no NIPBL mutation: a 6.5 Mb subtelomeric deletion of chromosome lq and an isochromosome $18 \mathrm{p}$. There is some phenotypic overlap between CdLS and terminal $\mathrm{lq}$ deletions. Indeed, both syndromes share some non-specific dysmorphic features (such as long philtrum, downturned corners of the mouth, and micrognathia) as well as heart defects and gastroesophageal reflux. ${ }^{16}{ }^{17}$ Interestingly, patient 2 presented a combination of monosomy lqter features (such as absence of corpus callosum) and characteristic CdLS features (arched eyebrows with synophrys, hirsutism, thin upper lip, behavioural problems, complete absence of speech, and short hands and feet). This observation suggests that some children diagnosed with CdLS may have a lqter deletion or, alternatively, that a second CdLS locus could map to lqter. It is therefore tempting to regard the genes mapping to this interval (genes involved in DNA repair $(K A B)$, cell signalling, differentiation, and apoptosis (AKT3), transcriptional regulation (ZNF283, $E L Y S)$, and purine nucleotide biosynthesis (ADSS)) as candidate genes in CdLS patients with neither chromosomal anomaly nor NIPBL mutation.

Similarly, tetrasomy $18 \mathrm{p}$ shares common features with CdLS (namely low birth weight, microcephaly, mental retardation, feeding difficulties, small nose, long philtrum, strabismus, and seizure ${ }^{18-20}$ ) and the behavioural phenotype of our isochromosome 18p patient is also consistent with CdLS (hyperactivity, sleep disturbances, repetitive behaviour, and minimal speech). By contrast, other features characteristic of isochromosome $18 \mathrm{p}$, namely microstomia, prominent upper lip, pinched nose, asymmetric long face, long and narrow fingers/toes, clenched hand/camptodactyly, spasticity, slender habitus, and scoliosis were not observed in patient $1 .{ }^{18}$ Differences in either parental origin or mechanism of formation of the isochromosomes may provide a molecular explanation for the discordant phenotypes between patient 1 and the previously reported individuals with $\mathrm{i}(18 \mathrm{p}) .{ }^{19}{ }^{20}$

The observation of unusual dysmorphic features in one CdLS patient with a NIPBL mutation and the absence of any distinctive feature in CdLS patients with or without NIPBL mutation in our series make the establishment of genotypephenotype correlations difficult. Our findings support the genetic heterogeneity of CdLS and emphasise the importance of molecular cytogenetic studies in CdLS patients without NIPBL mutation.

\section{ACKNOWLEDGEMENTS}

We thank all families for their participation in this study.

\section{ELECTRONIC-DATABASE INFORMATION}

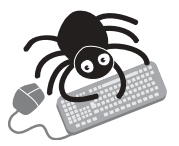

The following URLs are mentioned in this study: http:// www.ensembl.org/Homo_sapiens/cyłoview and www.genome.ucsc.edu.

\section{Authors' affiliations}

G Borck, D Sanlaville, M Rio, M Prieur, S Lyonnet, M Vekemans, A Munnich, L Colleaux, V Cormier-Daire, INSERM U393 and Département de Génétique Médicale, Hôpital Necker - Enfants Malades, Paris, France

R Redon, N P Carter, The Wellcome Trust Sanger Institute, Wellcome Trust Genome Campus, Hinxton, Cambridge CB10 1SA, UK

This work was supported by the Association Française du Syndrome de Cornélia de Lange (AFSCL). GB was supported by an INSERM fellowship (poste vert); RR by a Sanger Institute Postdoctoral Fellowship; and DS by PHRC grant AOM 02122.

Conflict of interest: none declared. 
Correspondence to: Valérie Cormier-Daire, INSERM U393, Hôpital Necker - Enfants Malades, 149 Rue de Sèvres, 75015 Paris, France; cormier@necker.fr

Revised version received 21 September 2004

Accepted for publication 23 September 2004

\section{REFERENCES}

1 Jackson L, Kline AD, Barr MA, Koch S. de Lange syndrome: a clinical review of 310 individuals. Am J Med Genet 1993;47:940-6.

2 Russell KL, Ming JE, Patel K, Jukofsky L, Magnusson M, Krantz ID. Dominant paternal transmission of Cornelia de Lange syndrome: a new case and review of 25 previously reported familial recurrences. Am J Med Genet 2001;104:267-76.

3 McKenney RR, Elder FF, Garcia J, Northrup H. Brachmann-de Lange syndrome: autosomal dominant inheritance and male-to-male transmission. Am J Med Genet 1996;66:449-52.

4 Krantz ID, Tonkin E, Smith M, Devoto M, Bottani A, Simpson C, Hofreiter M Abraham V, Jukofsky L, Conti BP, Strachan T, Jackson L. Exclusion of linkage to the CDL1 gene region on chromosome 3q26.3 in some familial cases of Cornelia de Lange syndrome. Am J Med Genet 2001;101:120-9.

5 Ireland M, English C, Cross I, Houlsby WT, Burn J. A de novo translocation $\mathrm{t}(3 ; 17)(\mathrm{q} 26.3 ; \mathrm{q} 23.1)$ in a child with Cornelia de Lange syndrome. J Med Genet 1991;28:639-40.

6 Wilson WG, Kennaugh JM, Kugler JP, Wyandt HE. Reciprocal translocation $14 \mathrm{q} ; 2 \mathrm{lg}$ in a patient with the Brachmann-de Lange syndrome. J Med Genet 1983:20:469-71.

7 Tonkin ET, Smith $M$, Eichhorn $P$, Jones S, Imamwerdi B, Lindsay S, Jackson $M$, Wang TJ, Ireland M, Burn J, Krantz ID, Carr P, Strachan T. A giant novel gene undergoing extensive alternative splicing is severed by a Cornelia de Langeassociated translocation breakpoint at 3q26.3. Hum Genet 2004;115:139-48.

8 Krantz ID, McCallum J, DeScipio C, Kaur M, Gillis LA, Yaeger D, Jukofsky L, Wasserman N, Bottani A, Morris CA, Nowaczyk MJ, Toriello H, Bamshad MJ, Carey JC, Rappaport E, Kawauchi S, Lander AD, Calof AL, Li HH, Devoto M, Jackson LG. Cornelia de Lange syndrome is caused by mutations in NIPBL, the human homolog of Drosophila melanogaster Nipped-B. Nat Genet 2004;36:631-5.

9 Tonkin ET, Wang TJ, Lisgo S, Bamshad MJ, Strachan T. NIPBL, encoding a homolog of fungal Scc2-type sister chromatid cohesion proteins and fly Nipped-B, is mutated in Cornelia de Lange syndrome. Nat Genet 2004;36:636-41
10 Rollins RA, Morcillo P, Dorsett D. Nipped-B, a Drosophila homologue of chromosomal adherins, participates in activation by remote enhancers in the cut and Ultrabithorax genes. Genetics 1999;152:577-93.

11 Rollins RA, Korom M, Aulner N, Martens A, Dorsett D. Drosophila nipped-B protein supports sister chromatid cohesion and opposes the stromalin/Scc3 cohesion factor to facilitate long-range activation of the cut gene. Mol Cell Biol 2004;24:3100-11

12 Gillis LA, McCallum J, Kaur M, DeScipio C, Yaeger D, Mariani A, Kline AD, Li HH, Devoto M, Jackson LG, Krantz ID. NIPBL mutational analysis in 120 individuals with Cornelia de Lange syndrome and evaluation of genotypephenotype correlations. Am J Hum Genet 2004;75:610-23.

13 Colleaux L, Rio M, Heuertz S, Moindrault S, Turleau C, Ozilou C, Gosset P, Raoult O, Lyonnet S, Cormier-Daire V, Amiel J, Le Merrer M, Picq M, de Blois MC, Prieur M, Romana S, Cornelis F, Vekemans M, Munnich A. A novel automated strategy for screening cryptic telomeric rearrangements in children with idiopathic mental retardation. Eur J Hum Genet 2001;9:319-27.

14 Fiegler H, Carr P, Douglas EJ, Burford DC, Hunt S, Scott CE, Smith J, Vetrie D, Gorman P, Tomlinson IP, Carter NP. DNA microarrays for comparative genomic hybridization based on DOP-PCR amplification of BAC and PAC clones. Genes Chromosomes Cancer 2003:36:361-74.

15 Shaw-Smith C, Redon R, Rickman L, Rio M, Willatt L, Fiegler H, Firth H, Sanlaville D, Winter R, Colleaux L, Bobrow M, Carter NP. Microarray based comparative genomic hybridisation (array-CGH) detects submicroscopic chromosomal deletions and duplications in patients with learning disability/ mental retardation and dysmorphic features. J Med Genet 2004;41:241-8.

16 De Vries BB, Knight SJ, Homfray T, Smithson SF, Flint J, Winter RM. Submicroscopic subtelomeric lqter deletions: a recognisable phenotype? J Med Genet 2001;38:175-8.

17 Gentile M, Di Carlo A, Volpe P, Pansini A, Nanna P, Valenzano MC, Buonadonna AL. FISH and cytogenetic characterization of a terminal chromosome lq deletion: clinical case report and phenotypic implications. Am J Med Genet 2003;117A:251-4.

18 Callen DF, Freemantle CJ, Ringenbergs ML, Baker E, Eyre HJ, Romain D, Haan EA. The isochromosome 18p syndrome: confirmation of cytogenetic diagnosis in nine cases by in situ hybridization. Am J Hum Genet 1990;47:493-8.

19 Bugge M, Blennow E, Friedrich U, Petersen MB, Pedeutour F, Tsezou A, Ørum A, Hermann S, Lyngbye T, Sarri C, Avramopoulos D, Kitsiou S, Lambert JC, Guzda M, Tommerup N, Brøndum-Nielsen K. Tetrasomy 18p de novo: parental origin and different mechanisms of formation. Eur J Hum Genet 1996;4:160-7.

20 Kotzot D, Bundscherer G, Bernasconi F, Brecevic L, Lurie IW, Basaran S Baccicchetti C, Holler A, Castellan C, Braun-Quentin C, Pfeiffer RA, Schinzel A. Isochromosome 18p results from maternal meiosis II nondisjunction. Eur J Hum Genet 1996;4:168-74. 